\title{
Low-Level Toxic Metal Exposure in Healthy Weaning-Age Infants: Association with Growth, Dietary Intake, and Iron Deficiency
}

\author{
Jungil Choi ${ }^{1}$, Ju Young Chang ${ }^{2,3, *}$, Jeana Hong ${ }^{4}$, Sue Shin ${ }^{5,6}$, Jeong Su Park ${ }^{5}$ and Sohee Oh ${ }^{7}$ \\ 1 Department of Electrical Engineering and Computer Science, Seoul National University, Seoul 08826, Korea; \\ gonasa82@snu.ac.kr \\ 2 Department of Pediatrics, Seoul National University College of Medicine, Seoul 03080, Korea \\ 3 Department of Pediatrics, Seoul Metropolitan Government Seoul National University Boramae Medical \\ Center, Seoul 07061, Korea \\ 4 Department of Pediatrics, Kangwon National University School of Medicine, Chuncheon 24289, Korea; \\ dochong@hanmail.net \\ 5 Department of Laboratory Medicine, Seoul National University College of Medicine, Seoul 03080, Korea; \\ jeannie@snu.ac.kr (S.S.); mdjs0721@naver.com (J.S.P.) \\ 6 Department of Laboratory Medicine, Seoul Metropolitan Government Seoul National University Boramae \\ Medical Center, Seoul 07061, Korea \\ 7 Department of Medical Statistics, Seoul Metropolitan Government Seoul National University Boramae \\ Medical Center, Seoul 07061, Korea; oh.sohee@gmail.com \\ * Correspondence: jychang7@snu.ac.kr; Tel.: +82-2-870-2362
}

Academic Editor: Paul B. Tchounwou

Received: 13 February 2017; Accepted: 31 March 2017; Published: 6 April 2017

\begin{abstract}
Even low levels of toxic metal exposure ( $\mathrm{As}, \mathrm{Cd}, \mathrm{Hg}$, and $\mathrm{Pb}$ ) in infancy might be harmful to children's development. This study investigated toxic metal exposure on healthy weaning-age infants and its relationship with growth, diet, and iron/anemia status. The weight, height, head circumference, whole blood levels of four toxic metals, hemoglobin, and serum ferritin of healthy infants was measured. Among 210 infants with a median age of 11.4 months (interquartile range: 10.5-12.0), the median levels of $\mathrm{As}, \mathrm{Cd}, \mathrm{Hg}$, and $\mathrm{Pb}$ were $1.2 \mu \mathrm{g} / \mathrm{L}, 0.05 \mu \mathrm{g} / \mathrm{L}, 0.8 \mu \mathrm{g} / \mathrm{L}$, and $0.83 \mu \mathrm{g} / \mathrm{dL}$, respectively. In adjusted linear regression models, post-birth weight gain $(\mathrm{Pb})$ and current head circumference $(\mathrm{As}, \mathrm{Pb})$ were negatively associated with toxic metal levels. In multiple linear regression or logistic regression analysis, the duration of breastfeeding (all four metals), perceived adequacy of rice-based food intake (As), regular fish intake (As, $\mathrm{Hg}$ ), and iron deficiency with/without anemia $(\mathrm{Cd}, \mathrm{Pb})$ were associated with increased toxic metal levels. Although levels of toxic metals may not usually be high in this population, individual exposure risk may need to be assessed after considering the type of feeding or intake of complementary foods and the iron/anemia status while evaluating growth status during late infancy.
\end{abstract}

Keywords: arsenic; cadmium; mercury; lead; infant; breast-feeding; diet; iron deficiency; growth; head circumference

\section{Introduction}

Arsenic, cadmium, mercury, and lead are established or potentially neurotoxic and genotoxic metals that lead to serious health problems in the case of human exposure [1-4]. Excessive exposure to these toxic metals can irreversibly damage normal infant development [5-8]. Recently, even low-level toxic metal exposure, unrelated to environmental exposure in high-risk residential areas, has been reported to adversely affect the normal physical growth of fetuses, infants and/or older children [9-12]. 
Among the four toxic metals, $\mathrm{Pb}$ is the one that is best known to impede children's growth, as it accumulates in the long bones and leads to bone damage $[8,13]$. Both prenatal and postnatal low-level $\mathrm{Pb}$ exposure $(<5.0 \mu \mathrm{g} / \mathrm{dL})$ has been reported to be inversely associated with post-birth growth of Korean infants and children $[12,14,15]$. However, few studies have investigated the dose-response association of low-level postnatal $\mathrm{Pb}$ exposure and the subsequent postnatal growth of children in late infancy, which is generally regarded as a high-risk period for $\mathrm{Pb}$ exposure [16,17]. For $\mathrm{As}, \mathrm{Cd}$, or $\mathrm{Hg}$, prenatal low-level exposure has been reported to have unfavorable effects on intrauterine or post-birth growth in some studies [9,10,18-20]. However, evidence of this is inconsistent in the current literature $[11,13,21]$. Moreover, studies on the effects of low-level postnatal As, Cd, or $\mathrm{Hg}$ exposure on the postnatal growth of infants or children are scarce as well. In addition, most studies investigated the effect of a single metal; only a few studies have simultaneously evaluated and compared the effect of low levels of multiple toxic metals on the growth of infants or children in the same population [22-24]. Factors such as different levels of exposure to toxic metals, differing amounts of materials that counteract or augment the harmful action of the toxic metals, or incomplete adjustment for other growth-affecting factors might contribute to the mixed results among previous studies $[11,12,25,26]$.

The weaning period, also known as the period of complementary feeding $(\mathrm{CF})$, is critical to the physical and mental development of children [27]; this may also be a critical period for the examination of the association between toxic metal exposure and children's growth and development. During this period, infants are exposed to toxic metals through dietary intake, putting contaminated non-food objects into their mouths, and indirect smoking [17]. Among these, diet may be the most important source of toxic metal exposure among the general population [28]. Both breastmilk and solid food can be important sources of toxic metal exposure during infancy.

All four toxic metals have been reported to be transmitted to babies by breastfeeding, although the degree of excretion of toxic metals in breastmilk seems different for different toxic metals [29]. Formula and its mixing water have also been reported as sources of toxic metal exposure [30,31]. The exposure pattern to toxic metals through the intake of contaminated solid foods may be similar to that of adults living in the same area. In Korea, the main source of complementary food usually includes rice-based food, red meat, fish and vegetables. However, rice can have elevated As levels [32]. Korean rice contained a similar amount of As to that of U.S. rice or Taiwan rice, although the level is distinctively lower than that of Bangladeshi rice [33-35]. Rice has been reported as an important source of As exposure among Korean immigrants in the US [36]. Fish intake has also been reported to be associated with increased As exposure in Korean adults and increased Hg exposure in Korean children [25,37]. According to a previous study on Korean children, grains, fish, shellfish, and seaweeds were important sources of $\mathrm{Cd}$ exposure; sources of $\mathrm{Pb}$ exposure were fruits, vegetables, and grains, rather than meats [38]. As, Cd, and $\mathrm{Hg}$ levels were higher among Korean adults than in those reported in western countries in a recent Korean national environmental health survey [39].

In addition, during the weaning period, infants are more likely to lack essential trace elements, which may serve to counteract the effects of toxic minerals $[27,40]$. For example, iron deficiency is the most common during this period. Childhood iron deficiency causes not only anemia but also retarded physical development [41]. In addition, if iron deficiency occurs during the first year of life, then permanent neural system disorders could arise [42]. Iron has also been reported to be involved in the metabolism of toxic metals, and iron deficiency has been reported to increase the absorption of $\mathrm{Cd}$, $\mathrm{Pb}$, and other toxic metals [43].

Nevertheless, population-based epidemiological studies examining the relationships among diet intake, iron status, and the toxic metal burden in weaning-age infants are limited. In addition, few studies have evaluated blood levels of toxic metals in this age group, especially in Korea. Previously, we investigated postnatal $\mathrm{Hg}$ exposure and its relationships with anthropometry and dietary factors in healthy Korean weaning-age infants [25]. In the present study, we investigated the exposure levels of four potentially growth-affecting toxic metals ( $\mathrm{As}, \mathrm{Cd}, \mathrm{Hg}$, and $\mathrm{Pb}$ ) in a different population with similar characteristics. The aim of this study was to explore the relationship between 
growth, feeding method, diet during the weaning period, iron levels, and the heavy toxic metal burden in weaning-age Korean infants.

\section{Materials and Methods}

\subsection{Subjects and Study Design}

This study was conducted in healthy infants who visited the Pediatric Clinic of Seoul Metropolitan Government, Seoul National University, Boramae Medical Center for health examinations and iron deficiency screenings from July 2014 to June 2016. All study participants resided in Seoul, Korea and were covered by self-paid national medical insurance with no fully or partially paid medical care. Inclusion criteria for children were as follows: ranging from 8 to 23 months in age and healthy; no intake of herbal medicine, iron, or zinc supplements in the past three months; no acute febrile disease or acute gastrointestinal disease in the past two weeks; and no evidence of other acute or chronic diseases affecting growth on physical examination or in medical history. The study protocol was approved by the Boramae Hospital Institutional Review Board (16-2013-55, 16-2015-83), and written informed consent was obtained from the parents of all participants. The estimated number of subjects was greater than 186 according to sample size calculations based on our preliminary data (type I error $=0.05$, power $=0.8$, partial correlation coefficient between head circumference $\mathrm{Z}$ scores and blood As levels $=-0.204$ ).

Each infant's weight, height, and head circumference was measured by experienced nurse, as previously described [40]. An experienced pediatrician collected birth-related, parents-related and dietary information from his/her parents through modified validated questionnaires as described previously [25]. Birth-related information included birth order, gestational age, birth weight, head circumference at birth, mother's age at delivery, and type of delivery (Table 1). Head circumference at birth was collected only in a subset of participants, whose parents showed the records for anthropometry at birth or whose electronic medical records at birth were available. Information on the mother's smoking status before pregnancy and during pregnancy and the father's indoor smoking status was also collected. For participants enrolled from July 2015, the parents' highest education level was obtained. Dietary information included the type of feeding, duration of feeding, and the dominant method of feeding during early and late infancy. Information on CF intake patterns was also collected, including the starting age for rice, red meat, and fish consumption and the recent average daily amounts of rice-based foods and red meat intake. The parents' subjective assessment on the adequacy of CF intake was re-evaluated by the same experienced pediatrician based on the information provided on recent average rice-based food and red meat intake (Table 1).

Table 1. Demographic, anthropometric, and diet-related parameters and iron status of 210 infants.

\begin{tabular}{lc}
\hline \multicolumn{1}{c}{ Characteristics } & Value \\
\hline Age, months $^{\text {a }}$ & $11.4(10.5,12.0)$ \\
\hline Sex, $n$ & \\
\hline Male & 97 \\
Female & 113 \\
\hline Birth order & 157 \\
\hline First & 53 \\
$\geq$ Second & \\
\hline Mother's age at delivery & 22 \\
\hline$<30$ years & 188 \\
\hline 30 years & 148 \\
\hline Type of birth, $n$ & 62 \\
\hline Vaginal delivery & \\
Surgical delivery & \\
\hline
\end{tabular}


Table 1. Cont.

\begin{tabular}{|c|c|}
\hline Characteristics & Value \\
\hline Gestational age, weeks ${ }^{\text {a }}$ & $39.0(38.0,40.0)$ \\
\hline \multicolumn{2}{|l|}{ Anthropometry, Z-score b } \\
\hline $\begin{array}{l}\text { Birthweight, } \mathrm{kg}^{\mathrm{a}} \\
\text { Birthweight } \\
\text { Weight for age } \\
\text { WAZ-BWZ } \\
\text { Height for age } \\
\text { Head circumference at birth, cm }{ }^{\mathrm{c}} \\
\text { Head circumference at birth c } \\
\text { Head circumference for age } \\
\text { Post-birth growth of head circumference c,d }\end{array}$ & $\begin{array}{c}3.24(3.02,3.48) \\
-0.08 \pm 0.73 \\
0.65 \pm 0.82 \\
0.73 \pm 0.89 \\
0.53 \pm 1.09 \\
34.0(33.5,35.0) \\
0.08 \pm 0.87 \\
0.44 \pm 0.83 \\
0.29 \pm 1.12\end{array}$ \\
\hline \multicolumn{2}{|l|}{ Feeding type, $n$} \\
\hline $\begin{array}{l}\text { Exclusively/mostly breastfed } \\
\text { Mixed fed } \\
\text { Mostly formula fed } \\
\text { Duration of breastfeeding, months a } \\
\text { Duration of CF intake, months a }\end{array}$ & $\begin{array}{c}95 \\
49 \\
66 \\
10.0(5.0,11.4) \\
5.0(5.0,6.0)\end{array}$ \\
\hline \multicolumn{2}{|l|}{ Adequacy of rice-based food intake, $n$} \\
\hline $\begin{array}{l}\text { Adequate } \\
\text { Poor } \\
\text { Duration of red meat intake, months }{ }^{\text {a }}\end{array}$ & $\begin{array}{c}163 \\
47 \\
5.0(4.0,6.0)\end{array}$ \\
\hline \multicolumn{2}{|l|}{ Adequacy of red meat intake, $n$} \\
\hline $\begin{array}{l}\text { Adequate } \\
\text { Poor }\end{array}$ & $\begin{array}{c}166 \\
44\end{array}$ \\
\hline \multicolumn{2}{|l|}{ Regular fish intake, $n$} \\
\hline $\begin{array}{l}\text { Presence } \\
\text { Absence } \\
\text { Duration of fish intake, months }{ }^{\text {a }}\end{array}$ & $\begin{array}{c}121 \\
89 \\
1.0(0.0,3.0) \\
\end{array}$ \\
\hline \multicolumn{2}{|l|}{ Iron status, $n$} \\
\hline $\begin{array}{l}\text { Deficiency } \\
\text { No deficiency } \\
\text { Iron deficiency anemia }\end{array}$ & $\begin{array}{c}44 \\
166 \\
18\end{array}$ \\
\hline \multicolumn{2}{|l|}{ Mother's smoking before pregnancy } \\
\hline $\begin{array}{l}\text { No } \\
\text { Yes }\end{array}$ & $\begin{array}{c}202 \\
8\end{array}$ \\
\hline \multicolumn{2}{|l|}{ Father's indoor smoking } \\
\hline $\begin{array}{l}\text { No } \\
\text { Yes }\end{array}$ & $\begin{array}{c}164 \\
46\end{array}$ \\
\hline
\end{tabular}

\footnotetext{
a The values are presented as the median and interquartile range; ${ }^{\mathrm{b}}$ The values are presented as the mean and standard deviation ( $95 \%$ confidence interval, CI); ${ }^{\mathrm{c}}$ The measurements were evaluated in 112 infants whose parents provided their babies' records for head circumference at birth or whose electronic medical records at birth were available; ${ }^{\mathrm{d}}$ The values were calculated as the difference in the current head circumference $Z$ scores minus the head circumference $Z$ scores at birth. WAZ-BWZ: The difference of the weight for age $Z$ scores at the time of the study and birth weight $Z$ scores; $C F$ : Complementary feeding.
}

\subsection{Blood Tests}

To diagnose iron deficiency (ID) and iron deficiency anemia (IDA), complete blood count, serum iron and ferritin concentrations, as well as total iron-binding capacity were measured from the venous blood samples of infants as previously described [25,40]. The $\mathrm{As}, \mathrm{Cd}, \mathrm{Hg}$, and Pb levels in the same venous whole blood samples of the infants were determined using Inductively-Coupled Plasma Mass Spectrometry (Agilent 7700, Santa Clara, CA, USA) at the Green Cross Reference Laboratory (Yongin-City, Kyunggi-do, Korea) as previously described [25]. 


\subsection{Definition}

Anthropometry at birth and at the study time was expressed as a Z-score according to age and sex using the Anthro software (version 3.2.2., January 2011) [44]. Post-birth weight gain was expressed as the difference in Z-scores (WAZ-BWZ), which was calculated as the difference in Z-scores for weight for age (WAZ) and the Z-scores for birth weight (BWZ) at the time of the study.

The dominant feeding method was categorized as exclusively/mostly breastfeeding, mostly formula feeding, and mixed feeding. Exclusively/mostly breastfeeding and mostly formula feeding were defined as previously described [25]. The infants who were not classified as mostly breastfed or mostly formula fed were defined as have mixed feeding. The duration of breastfeeding was counted as the period of total breastfeeding ( $\geq 2$ times/day).

Higher toxic metal levels were defined as those equal to or greater than median values, and lower levels as those less than median values. The upper limits of blood metal levels except As, followed those recommended by the U.S. Department of Labor, Environmental Protection Agency (EPA), and Centers for Disease Control and Prevention (CDC) of the US as follows: Cd, $5 \mu \mathrm{g} / \mathrm{L}$; $\mathrm{Hg}, 5.8 \mu \mathrm{g} / \mathrm{L} ; \mathrm{Pb}, 5 \mu \mathrm{g} / \mathrm{dL}[3,15,45]$. ID was defined as (1) a serum ferritin level of $<12 \mathrm{ng} / \mathrm{mL}$ or (2) mean corpuscular volume of $<70 \mathrm{fL}$ and transferrin saturation of $<16 \%$ [46]. IDA was defined as $\mathrm{Hb}<11 \mathrm{~g} / \mathrm{dL}$ plus ID.

\subsection{Statistical Analysis}

All analyses were performed using PASW software (version 20.0; SPSS Inc., Chicago, IL, USA). Normality was tested by visually inspecting normal distribution plots and histograms as well as residual plots of variables. Normally distributed variables such as Z-scores were expressed as mean \pm standard deviation and were tested using the Student's $t$-test. Non-normally distributed variables including blood toxic metal levels were expressed as the median and interquartile range (IQR) and were tested using the Mann-Whitney test or Kruskal-Wallis test. Categorical data were compared using the Pearson's $\chi^{2}$ test. Correlations between continuous variables were assessed using either the Pearson correlation coefficient or the Spearman rank correlation coefficient. Based on the results of correlation tests and simple linear regression tests, two adjusted linear regression models for post-birth weight gain Z-scores and head circumference Z-scores were built. Explanatory variables included potential growth-affecting parameters, including blood toxic metal levels, birth weight, sociodemographic and feeding-related factors, and iron and anemia status, using a backward elimination method. In addition, two adjusted linear regression models (for $\mathrm{As}$ and $\mathrm{Hg}$ ) and two logistic regression models (for $\mathrm{Cd}$ and $\mathrm{Pb}$ ) were used to build four prediction models for blood toxic metal levels, based on the participants' sociodemographic and feeding-related factors and iron status using a backward elimination method. For these analyses, the common logarithm-transformed values (base 10) of $\log \mathrm{As}$ and $\mathrm{Hg}(\mathrm{ng} / \mathrm{dL}$ ) were used because As or $\log$ As and $\mathrm{Hg}$ levels were not normally distributed. Thus, for As, the log of the $\log$-change score of As levels (ng/dL), $\log (\log A s)$, was used to further improve the normality of the residuals. For $\mathrm{Cd}$ and $\mathrm{Pb}$, categorical values based on median values (Supplementary Tables S1 and S2) were used instead because the transformation of measured metal levels into normally distributed values was not possible.

\section{Results}

\subsection{Characteristics of the Study Subjects}

A total of 210 term infants were included in this study, with a median age of 11.4 months (range: 8.7-22.0; IQR: 10.5-12.0), and the sex ratio was 97 male infants to 113 female infants $(\mathrm{M} / \mathrm{F}=0.86)($ Table 1). The birthweight for age (WAZ) was $-0.08(95 \% \mathrm{CI}:-0.18-0.02)$, and the number of underweight (WAZ $<-2$ ) and overweight infants (WAZ $>2$ ) was 0 and 10, respectively. The anthropometric Z-scores for weight, height, and head circumference are summarized in Table 1. In terms of feeding type, 95 infants $(45.2 \%)$ were exclusively or mostly breastfed until late infancy 
for a median time of 11.4 months (IQR: 10.5-12.0), and $66(31.4 \%)$ were exclusively or mostly formula-fed. The median duration of complementary feeding was 5.0 months (IQR: 5.0-6.0). Rice-based porridge/cooked rice ingestion and red meat intake were perceived as adequate in $163(71.5 \%)$ and $166(72.8 \%)$ infants, respectively. There were $121(57.6 \%)$ infants that were fed fish more than once per week. ID and IDA were observed in $44(21.0 \%)$ and $18(8.6 \%)$ infants, respectively. In terms of the related characteristics of parents, no maternal smoking history during pregnancy was identified in any of the participants. Indoor smoking by the father was identified in $46(21.7 \%)$ participants. Among 99 participants who were evaluated from July 2015, the highest education level of the fathers and mothers were postgraduate education $(17.2 \%$ and $18.2 \%)$, college or university graduate (71.7\% and $71.7 \%)$, and high school graduate $(11.1 \%$ and $10.1 \%)$.

\subsection{Blood Toxic Metal Levels and Their Interrelationship}

Among the 210 infants, the median blood $\mathrm{As}, \mathrm{Cd}, \mathrm{Hg}$, and $\mathrm{Pb}$ levels were $1.2 \mu \mathrm{g} / \mathrm{L}$ (IQR 1.62-2.26), $0.05 \mu \mathrm{g} / \mathrm{L}$ (IQR 0.06-0.07), $0.8 \mu \mathrm{g} / \mathrm{L}$ (IQR 0.90-0.11), and $0.83 \mu \mathrm{g} / \mathrm{dL}$ (IQR 0.86-1.05), respectively (Table 2). Blood $\mathrm{Cd}, \mathrm{Hg}$, and Pb levels in all infants were lower than $5 \mu \mathrm{g} / \mathrm{L}, 5.8 \mu \mathrm{g} / \mathrm{L}$, and $5 \mu \mathrm{g} / \mathrm{dL}$, respectively. There was a weak but significant correlation among blood $\mathrm{As}, \mathrm{Cd}$, and $\mathrm{Hg}$ levels (As-Cd, $\mathrm{r}=0.23, p=0.001$; As-Hg, $\mathrm{r}=0.46, p<0.001$; $\mathrm{Cd}-\mathrm{Hg}, \mathrm{r}=0.23, p<0.001$ ); however, blood $\mathrm{Pb}$ levels were not significantly correlated with any other blood toxic metal levels.

Table 2. Blood toxic metal levels in 210 infants.

\begin{tabular}{cccccccc}
\hline & Geometric Mean & \multicolumn{3}{c}{ Percentiles } & \multicolumn{2}{c}{ Maximum } \\
\cline { 2 - 8 } & $\mathbf{( 9 5 \% ~ C I ) ~}$ & $\mathbf{1 0}$ & $\mathbf{2 5}$ & $\mathbf{5 0}$ & $\mathbf{7 5}$ & $\mathbf{9 0}$ & Value \\
\hline Blood metal level & & & & & & & \\
$\mathrm{As}(\mu \mathrm{g} / \mathrm{L})$ & $1.94(1.62,2.26)$ & 0.5 & 0.8 & 1.2 & 2.0 & 4.4 & 11.9 \\
$\mathrm{Cd}(\mu \mathrm{g} / \mathrm{L})$ & $0.067(0.06,0.073)$ & 0.02 & 0.04 & 0.05 & 0.09 & 0.11 & 0.4 \\
$\mathrm{Hg}(\mu \mathrm{g} / \mathrm{L})$ & $0.99(0.90,1.08)$ & 0.34 & 0.56 & 0.8 & 1.24 & 1.8 & 4.2 \\
$\mathrm{~Pb}(\mu \mathrm{g} / \mathrm{dL})$ & $0.96(0.86,1.05)$ & 0.12 & 0.52 & 0.83 & 1.23 & 1.82 & 3.5 \\
\hline
\end{tabular}

\subsection{Association between Blood Toxic Metal Levels and Growth Parameters}

Because there was a significant correlation between blood $\mathrm{Pb}$ levels and post-birth weight gain $(\mathrm{r}=-0.202, p=0.003)$ or head circumference for age $\mathrm{Z}$ scores (HCAZ) $(\mathrm{r}=-0.190, p=0.006)$ and blood As level and HCAZ ( $r=-0.159, p=0.023$ ) (Supplementary Figures S1 and S2), we performed multiple linear regressions with growth-related parameters as dependent variables (Table 3 ). There was still a significant correlation between weight gain after birth and blood $\mathrm{Pb}$ levels $(\mathrm{B}=-0.238, p=0.003)$ after adjustment for other potential growth-related parameters. The current head circumference was also significantly correlated with blood $\mathrm{Pb}$ levels $(\mathrm{B}=-0.213, p=0.007)$ and blood As levels $(\mathrm{B}=-0.053$, $p=0.020$ ) after adjustment for other potential growth-related parameters.

Table 3. Adjusted linear regression models for growth parameters in 210 infants according to possible growth-related factors including toxic metal levels.

\begin{tabular}{cccccc}
\hline \multirow{2}{*}{$\begin{array}{c}\text { Dependent } \\
\text { Variables }\end{array}$} & \multirow{2}{*}{$\begin{array}{c}\text { Independent } \\
\text { Variables }\end{array}$} & \multicolumn{2}{c}{ Unadjusted } & \multicolumn{2}{c}{ Adjusted } \\
\cline { 3 - 5 } & & B (SE) & $p$-Value & B (SE) & $p$-Value \\
\hline \multirow{2}{*}{ WAZ-BWZ } & BWZ & $-0.601(0.073)$ & $<0.001$ & $-0.586(0.073)$ & $<0.001$ \\
& Iron deficiency & $0.217(0.150)$ & 0.150 & $0.223(0.131)$ & 0.09 \\
& Blood Pb levels & $-0.202(0.089)$ & 0.024 & $-0.238(0.078)$ & 0.003 \\
\hline \multirow{2}{*}{$\mathrm{HCAZ}$} & BWZ & $0.352(0.075)$ & $<0.001$ & $0.358(0.074)$ & $<0.001$ \\
& Blood Pb levels & $-0.206(0.083)$ & 0.014 & $-0.213(0.078)$ & 0.007 \\
& Blood As levels & $-0.057(0.024)$ & 0.018 & $-0.053(0.022)$ & 0.020 \\
\hline
\end{tabular}

WAZ-BWZ: The difference of the weight for age $\mathrm{Z}$ scores at the time of the study and birth weight $\mathrm{Z}$ scores; HCAZ: head circumference for age $Z$ scores. 


\subsection{The Relationship between Feeding and Dietary Factors and Blood Toxic Metal Levels}

Blood $\mathrm{Cd}, \mathrm{Hg}$, and $\mathrm{Pb}$ levels were significantly higher in the infants who were mostly breastfed until late infancy compared to those who were mostly formula-fed ( $\mathrm{Cd}: p=0.001 ; \mathrm{Hg}$ and $\mathrm{Pb}: p<0.001$; Table 4). The duration of breastfeeding was also significantly correlated with each blood metal level (As: $\mathrm{r}=0.181, p=0.009 ; \mathrm{Cd}: \mathrm{r}=0.273, p<0.001 ; \mathrm{Hg}: \mathrm{r}=0.394, p<0.001 ; \mathrm{Pb}: \mathrm{r}=0.427, p<0.001$ ).

Table 4. Blood toxic metal levels according to dietary factors and iron status.

\begin{tabular}{|c|c|c|c|c|}
\hline Parameters & $\operatorname{As}^{a}(\mu g / L)$ & $C d^{a}(\mu g / L)$ & $\mathrm{Hg}^{\mathrm{a}}(\mu \mathrm{g} / \mathrm{L})$ & $\mathrm{Pb}^{\mathrm{a}}(\mu \mathrm{g} / \mathrm{dL})$ \\
\hline \multicolumn{5}{|l|}{ Feeding type } \\
\hline Exclusively/mostly breastfed & $1.4(1.0,2.1)$ & $0.06(0.05,0.10)$ & $1.1(0.7,1.6)$ & $1.12(0.77,1.63)$ \\
\hline Mixed fed & $1.0(0.7,1.7)$ & $0.04(0.03,0.08)$ & $0.8(0.5,1.1)$ & $0.81(0.51,1.11)$ \\
\hline Mostly formula fed & $1.1(0.6,2.1)$ & $0.05(0.03,0.07)$ & $0.7(0.4,1.0)$ & $0.62(0.39,0.82)$ \\
\hline$p$-Value ${ }^{b}$ & 0.065 & 0.001 & $<0.001$ & $<0.001$ \\
\hline \multicolumn{5}{|c|}{ Adequacy of rice-based food intake } \\
\hline Adequate & $1.4(0.9,2.2)$ & $0.06(0.04,0.10)$ & $0.8(0.6,1.3)$ & $0.74(0.51,1.12)$ \\
\hline Poor & $1.0(0.6,1.7)$ & $0.05(0.03,0.07)$ & $0.7(0.5,1.2)$ & $1.06(0.77,1.58)$ \\
\hline$p$-Value & 0.013 & 0.079 & 0.219 & 0.001 \\
\hline \multicolumn{5}{|l|}{ Adequacy of red meat intake } \\
\hline Adequate & $1.3(0.9,2.1)$ & $0.06(0.04,0.10)$ & $0.8(0.6,1.3)$ & $0.75(0.51,1.14)$ \\
\hline Poor & $1.0(0.7,1.9)$ & $0.05,0.03,0.07)$ & $0.8(0.5,1.2)$ & $1.04(0.77,1.53)$ \\
\hline$p$-Value & 0.069 & 0.236 & 0.435 & 0.004 \\
\hline \multicolumn{5}{|l|}{ Regular fish intake } \\
\hline Presence & $1.5(0.9,2.9)$ & $0.05(0.04,0.10)$ & $0.9(0.7,1.3)$ & $0.74(0.51,1.20)$ \\
\hline Absence & $1.0(0.7,1.6)$ & $0.05(0.04,0.08)$ & $0.7(0.5,1.2)$ & $0.97(0.59,1.27)$ \\
\hline$p$-Value & $<0.001$ & 0.678 & 0.006 & 0.063 \\
\hline \multicolumn{5}{|l|}{ Iron Status } \\
\hline Deficiency & $1.4(0.8,2.0)$ & $0.07(0.05,0.10)$ & $1.0(0.6,1.4)$ & $1.24(0.84,1.64)$ \\
\hline No deficiency & $1.2(0.8,2.0)$ & $0.05(0.03,0.08)$ & $0.8(0.5,1.2)$ & $0.75(0.51,1.10)$ \\
\hline$p$-Value & 0.752 & 0.029 & 0.134 & $<0.001$ \\
\hline \multicolumn{5}{|l|}{ Iron deficiency anemia } \\
\hline Presence & $1.5(1.0,2.0)$ & $0.06(0.05,0.08)$ & $0.9(0.6,1.5)$ & $1.44(1.14,1.80)$ \\
\hline Absence & $1.2(0.8,2.0)$ & $0.05(0.04,0.01)$ & $0.8(0.6,1.2)$ & $0.79(0.51,1.14)$ \\
\hline$p$-Value & 0.279 & 0.419 & 0.390 & $<0.001$ \\
\hline
\end{tabular}

There were significant associations between some dietary patterns during weaning and certain blood metal levels. Blood As levels were significantly higher in the infants with perceived adequacy of rice-based $\mathrm{CF}$ intake $(p=0.013)$. In contrast, blood $\mathrm{Pb}$ levels were significantly lower in those same infants $(p=0.001)$. Blood $\mathrm{Pb}$ levels were also significantly lower in the infants with perceived adequacy of red meat intake $(p=0.004)$. Blood As and $\mathrm{Hg}$ levels were significantly higher in the infants with regular fish intake ( $p<0.001, p=0.006$, respectively).

In adjusted linear regression models (Table 5) and adjusted logistic regression models (Table 6), the duration of breastfeeding was significantly associated with blood $\log (\log A s)(B=0.004, p=0.002)$, $\log \mathrm{Hg}(\mathrm{B}=0.028, p<0.001)$, higher $\mathrm{Cd}$ levels (adjusted odds ratio, a-OR: $1.1, p=0.019)$, and higher $\mathrm{Pb}$ levels (a-OR: 1.3, $p<0.001$ ). Perceived adequacy of rice-based $C F$ intake and duration of $C F$ intake were significantly associated with blood $\log (\log A s)(B=0.022, p=0.044 ; B=0.006, p=0.017$, respectively). Fish intake was significantly associated with blood $\log (\log A s)(B=0.036, p<0.001)$ and $\log \mathrm{Hg}$ levels $(\mathrm{B}=0.036, p<0.001)$. 
Table 5. Simple and multiple linear regression analysis of Log (log As) and Log Hg levels in 210 infants according to demographics, dietary parameters, and iron status.

\begin{tabular}{lcccc}
\hline \multirow{2}{*}{ Variables } & \multicolumn{2}{c}{ Unadjusted } & \multicolumn{2}{c}{ Adjusted } \\
\cline { 2 - 5 } & \multicolumn{1}{c}{ B (SE) } & $p$-Value & B (SE) & $p$-Value \\
\hline Log $(\log$ As) & & & & \\
\hline Duration of breastfeeding & $0.003(0.001)$ & 0.008 & $0.004(0.001)$ & 0.002 \\
Duration of CF & $0.009(0.003)$ & 0.001 & $0.006(0.003)$ & 0.017 \\
Adequate rice-based food intake & $0.031(0.011)$ & 0.007 & $0.022(0.011)$ & 0.044 \\
Regular fish intake & $0.038(0.009)$ & $<0.001$ & $0.036(0.009)$ & $<0.001$ \\
Mother's age at delivery $(\geq 30$ years) & $0.035(0.015)$ & 0.026 & $0.029(0.014)$ & 0.044 \\
\hline Log Hg & & & & \\
\hline Monthly age & $0.044(0.013)$ & 0.001 & $0.021(0.012)$ & 0.097 \\
Duration of breastfeeding & $0.028(0.005)$ & $<0.001$ & $0.028(0.005)$ & $<0.001$ \\
Duration of fish intake & $0.033(0.010)$ & 0.002 & $0.036(0.010)$ & $<0.001$ \\
\hline
\end{tabular}

Table 6. Simple and multiple logistic regression analysis of $\mathrm{Cd}$ and $\mathrm{Pb}$ levels in 210 infants according to demographics, dietary parameters, and iron status.

\begin{tabular}{|c|c|c|c|c|c|c|}
\hline Variables & Unadjusted Odds Ratio & $95 \%$ CI & $p$-Value & Adjusted Odds Ratio & $95 \%$ CI & $p$-Value \\
\hline \multicolumn{7}{|l|}{$\mathrm{Cd}$} \\
\hline Monthly age & 1.7 & $1.3,2.3$ & $<0.001$ & 1.7 & $1.3,2.4$ & 0.001 \\
\hline Male sex & 1.9 & $1.1,3.4$ & 0.028 & 1.8 & $1.0,3.4$ & 0.059 \\
\hline Duration of breastfeeding & 1.2 & $1.1,1.3$ & $<0.001$ & 1.1 & $1.0,1.2$ & 0.019 \\
\hline Iron deficiency & 3.0 & $1.3,7.0$ & 0.008 & 2.3 & $0.9,5.9$ & 0.071 \\
\hline \multicolumn{7}{|l|}{$\mathrm{Pb}$} \\
\hline Duration of breastfeeding & 1.3 & $1.2,1.4$ & $<0.001$ & 1.3 & $1.2,1.4$ & $<0.001$ \\
\hline Iron deficiency anemia & 19.3 & $2.5,147.7$ & 0.004 & 9.9 & $1.3,78.1$ & 0.030 \\
\hline Father's indoor smoking & 2.5 & $1.2,5.0$ & 0.013 & 2.7 & $1.2,6.0$ & 0.017 \\
\hline
\end{tabular}

\subsection{The Relationship between Iron Deficiency and Blood Toxic Metal Levels}

Blood $\mathrm{Cd}$ and $\mathrm{Pb}$ levels were significantly higher in infants with ID compared to those without ID (Cd: $p=0.029 ; \mathrm{Pb}: p<0.001$, Table 4). Blood Pb levels, but not blood Cd levels, were also significantly higher in infants with IDA compared to those without IDA $(p<0.001)$. Other blood metal levels were not correlated with ID or IDA.

In adjusted logistic regression models (Table 6), ID tended to be associated with higher blood Cd levels (a-OR: 2.3, $p=0.071$ ), and IDA was significantly associated with higher blood Pb levels (a-OR: 9.9, $p=0.030$ ).

\subsection{The Relationship between Other Sociodemographic Factors and Blood Toxic Metal Levels}

There were significant positive correlations between age and blood $\mathrm{As}, \mathrm{Cd}$, and $\mathrm{Hg}$ levels (As: $\mathrm{r}=0.282, p<0.001 ; \mathrm{Cd}: \mathrm{r}=0.278, p<0.001 ; \mathrm{Hg}: \mathrm{r}=0.278, p<0.001$ ). However, age was not significantly correlated with blood Pb levels. There was a tendency of a weak correlation between gestational age and blood $\mathrm{Hg}$ or Pb levels ( $\mathrm{Hg}: \mathrm{r}=0.135, p=0.051 ; \mathrm{Pb}: \mathrm{r}=0.118, p=0.088)$, although it was not significant. First birth order was significantly associated with higher blood Hg levels (0.91 (0.61, $1.26)$ vs. $0.66(0.47,1.15), p=0.026)$. Mother's age at delivery ( $\geq 30$ years) was significantly associated with higher As levels $(0.95(0.5,1.63)$ vs. 1.3 (0.83 vs. 2.08$), p=0.041)$. The father's indoor smoking was significantly associated with higher blood Pb levels $(0.75(0.47,1.15)$ vs. $1.04(0.72,1.52), p=0.002)$ (Supplemental Table S2). The highest education level of mothers $(n=99)$ was significantly associated with lower blood $\mathrm{Hg}$ levels (a college education or greater versus a high school graduate; 0.72 (0.5, $1.12)$ vs. $1.76(0.65,2.01), p=0.006)$. Sex, method of birth, and maternal smoking before pregnancy were not significantly correlated with any blood metal levels. 
In adjusted linear regression models (Table 5) or adjusted logistic regression models (Table 6), monthly age was significantly associated with higher blood Cd levels (a-OR: 1.7, $p=0.001$ ) and marginally associated with blood $\log \mathrm{Hg}$ levels $(\mathrm{B}=0.021, p=0.097)$. Male children tended to have higher Cd levels (a-OR: 1.8, $p=0.059)$. The mother's age at delivery ( $\geq 30$ years) was significantly associated with $\log (\log A s)$ levels $(B=0.029, p=0.044)$. The father's indoor smoking was significantly associated with higher $\mathrm{Pb}$ levels (a-OR: 2.7, $p=0.017$ ). Other demographic parameters were not significantly associated with any blood metal levels.

\section{Discussion}

This study shows that $\mathrm{Cd}, \mathrm{Hg}$, and $\mathrm{Pb}$ exposure in healthy Korean weaning-age infants residing in Seoul is usually below the upper limit suggested by the EPA and CDC of the U.S. [3,15,45]. Median Cd and $\mathrm{Hg}$ levels were distinctively lower in our subjects than in a small subset of Korean newborns or school-aged children, and $\mathrm{Pb}$ levels were slightly lower in our subjects than in Korean or western school-aged children [47-49]. The globally accepted upper normal limit blood level for As has not yet been established [50]. However, according to the $12 \mu \mathrm{g} / \mathrm{L}$ upper limit suggested by the Mayo Clinic in the U.S. [51], all infants had acceptable blood As levels. Still, according to the $1.0 \mu \mathrm{g} / \mathrm{L}$ upper limit from the Agency for Toxic Substances and Disease Registry [3], 66.7\% of our subjects had higher levels than desired. Although few studies investigating blood As levels among weaning-age infants are available in the literature, the geometric mean As value of the infants in our study was similar to the cord blood As levels of Nepal infants; blood As levels are distinctively lower than that of adults from high-risk areas such as Bangladesh, and distinctively higher than that of Western adults and children [52-55]. This matches the results from a previous Korean national study showing that urine As levels in Korean adults were similar to those from eastern Asia but much higher than those in western adults [56,57]. However, because blood and urine in Koreans may often contain a considerable amount of organic As through seafood ingestion (which is regarded as far less toxic than inorganic As), the differences in blood As levels between the infants in our study and the infants in western populations may not equal the differences in toxicity between them $[37,56]$.

Among the four toxic metals, only $\mathrm{As}$ and $\mathrm{Pb}$ levels were negatively associated with anthropometry of Korean weaning-age infants in adjusted linear regression models. As was only associated with current head circumference, whereas $\mathrm{Pb}$ was associated with both post-birth increase of weight and current head circumference. A direct comparison of the degree of the adverse influence of $\mathrm{As}$ and $\mathrm{Pb}$ on post-birth growth through blood levels might not be possible. However, $\mathrm{Pb}$ seemed to influence growth restriction factors to a greater degree in an adjusted linear model for current head circumference, although the range of $\mathrm{Pb}$ levels was lower in our subjects than in those from previous growth-related studies $[8,12,16]$. To our knowledge, this is a unique result showing that low level postnatal $\mathrm{Pb}$ exposure, mostly $<3 \mu \mathrm{g} / \mathrm{dL}$, may be associated with restricting post-birth growth, including head size increase of children during infancy. This study is also noteworthy because a significant inverse association between low to modest As exposure and post-birth anthropometry was observed among subjects who did not reside in previously known high-risk areas with As-contaminated water exceeding WHO standards $[29,58]$. Compared to the other three toxic metals, investigations on the association of low levels of prenatal or postnatal As exposure and post-birth anthropometry in children are extremely scarce. In addition, this is one of the first reports demonstrating the inverse association between low $\mathrm{As}$ and low $\mathrm{Pb}$ levels and post-birth growth within the same population in the weaning period, in which potential growth-affecting factors including ID or IDA and feeding type or diet adequacy were adjusted.

The method by which As restricts growth is unclear. Endocrine-disrupting properties leading to insulin-like growth factor 1 (IGF-1) suppression have been suggested as a mechanism of growth impairment [59]. Our study cannot explain the reason why As was associated with only current head circumference and not post-birth weight gain. It may be associated with the toxic nature of low As exposure itself and/or a specific exposure period during childhood. We cannot exclude 
the possibility that a smaller head circumference at birth associated with intrauterine As exposure may considerably contribute to the lower head circumference in this study, because brain growth is particularly vulnerable to intrauterine insult [60]. Our study might be limited in its ability to prove an independent association between postnatal As exposure and current head circumference because the cord-blood As levels were not investigated, although mother's age at delivery was adjusted, which might be associated with cord-blood As levels. In addition, as the current head circumference of our infants was mostly within normal range, the clinical significance of the observed inverse association between As and growth may need to be determined through further functional study. In a previous Nepal cohort, cord blood As levels, similar to ours, were associated with adverse neurodevelopment at birth, but not at 36 months of age [54]. Although many studies used the urinary As level as a biomarker for exposure [61], blood As has the advantage of reflecting the As burden in tissue compartments [55]. In general, blood As concentrations have been considered to reflect only recent exposure. However, considering that the feeding patterns and diet of weaning-age infants are usually repetitive once established and maintained long term, blood As levels can reflect long-term steady-state exposure [55]. We did not find an independent association between low-level post-birth $\mathrm{Cd}$ or $\mathrm{Hg}$ exposure and post-birth anthropometry, which is consistent with the results of a few previous studies [13,25]. It may be associated, at least in part, with much lower Cd levels in our subjects compared to newborns or older children in Korea or western countries [47,49].

Feeding type and breastfeeding duration were significantly correlated with all four metal levels in our study, which was consistent with the results of previous studies [29]. The relatively slow growth of breastfed infants compared with formula-fed infants during the first few years of life is well documented [62]. Consequently, it is important to adjust the type of feeding or amount and duration of breastfeeding to document the association between toxic metals and infant growth. In this study, although post-birth Z-scores were negatively correlated with the duration of breastfeeding, As and $\mathrm{Pb}$ levels were chosen as final explanatory variables, rather than feeding type or duration of breastfeeding, in the adjusted regression models for anthropometry, which was contrary to the case of $\mathrm{Hg}$ levels in our previous study [25]. Therefore, breastfeeding should be encouraged, and $\mathrm{As}$ and $\mathrm{Pb}$ exposure should be reduced as much as possible by controlling the diet and environment of breastfeeding mothers and their babies. In fact, in the case of As, there are also reports that the inorganic As secretion of breastmilk is decreased by increased methylation in lactating mothers; thus, the As concentration in breast milk is very low even in contaminated areas, unlike that of $\mathrm{Hg}[29,63]$. Pb levels seemed more affected by IDA than by CF type in our subjects. Given that prolonged breastfeeding is also a well-documented risk factor for ID or IDA $[64,65]$, prevention of ID or IDA can be one of the most important precautions for reducing toxic metal exposure in breastfed infants. In this study, ID was also found to be associated with higher $\mathrm{Cd}$ levels, which was consistent with the results from previous studies on adults and children $[43,66]$.

There was a significant correlation between the adequacy of specific food intake and specific toxic metal levels in weaning-age infants, similar to Korean adults and older children $[37,38]$. Although the amount of food intake was not precisely quantified in this study, the perceived adequacy of rice-based food intake was significantly associated with blood As levels and it tended to be associated with blood $\mathrm{Cd}$ levels as well. Infants with fish intake more than once per week also had increased blood As and $\mathrm{Hg}$ levels. In general, while As in both rice and breast milk is regarded as highly toxic inorganic As, seafood contains organic As, which does not induce substantial damage to the body because it is rapidly and completely excreted in the urine [63]. However, attention to the As exposure through seafood intake is also required, as recent studies showed increased levels of dimethylarsinic acid (DMA) in the urine of adult populations after seafood intake, which is far more toxic than organic As [67].

There are some limitations to this study. It was a single-center, cross-sectional study with a modest number of infants. Toxic metal levels were measured only once. Precise quantification of dietary intake was not performed. While blood is the preferred biomarker for $\mathrm{Pb}$ and $\mathrm{Hg}$ exposure, urine is 
the usual biomarker for As and Cd exposure in many studies. Finally, this study did not thoroughly adjust for environmental, genetic, social, and economic factors, which could potentially affect growth. Nevertheless, based on information about the medical insurance status, detailed addresses of the residence area, and smoking history of mothers, it is possible to assume that our subjects may likely not be at risk for a poor nutritional status or environmental exposure to toxic metals. In half of the study participants, the parents' highest education level was available, which showed that the proportion of highest education levels were higher in our study population than in the general Korean population with similar ages.

\section{Conclusions}

To our knowledge, this is a unique study in that it measured toxic metal levels of weaning-age infants using blood levels as biomarkers and obtained an integrated picture of the close association between anthropometry, breastfeeding, CF, and ID or IDA of infancy in the same population. Although $\mathrm{Cd}, \mathrm{Hg}$, and $\mathrm{Pb}$ exposure in healthy Korean weaning-age infants residing in Seoul is usually below the officially suggested upper limit, the As and $\mathrm{Hg}$ levels were found to be higher than those in western populations, as in Korean adults. Among the four toxic metals, As and $\mathrm{Pb}$ exposure showed significant negative associations with anthropometry in weaning-age infants. The toxic metal exposure levels were also significantly associated with the type of feeding or duration of breastfeeding, perceived adequacy of a specific diet, and iron and anemia status. Although levels of toxic metals may not usually be high in this population, individual exposure risk may need to be assessed after considering the type of feeding or intake of complementary foods and the iron/anemia status during evaluation of growth status. In addition, meticulous parental education for prevention of ID and IDA as well as efforts to maintain the appropriate iron status through screening or preventive iron intake are necessary.

Supplementary Materials: The following are available online at www.mdpi.com/1660-4601/14/4/388/s1, Figure S1: Correlation between blood lead levels and post-birth weight gain (WAZ-BWZ) (a), and head circumference for age Z scores (HCAZ) (b), Figure S2: Correlation between blood arsenic levels and head circumference for age Z scores (HCAZ), Table S1: Demographic, anthropometric, and diet-related parameters and iron status in two categories of infants according to the median values of blood cadmium levels, Table S2: Demographic, anthropometric, and diet-related parameters and iron status in two categories of infants according to the median values of blood lead levels.

Acknowledgments: This study was supported by grant No. 16-2013-55 from the SK Telecom Research Fund, Green Cross 2015-83 Research Fund, and grant no. 03-2017-16 from the Seoul Metropolitan Government-Seoul National University Boramae Medical Center Research Fund.

Author Contributions: Ju Young Chang conceived and designed the study. Ju Young Chang and Jungil Choi contributed to writing the paper. Jeana Hong, Jungil Choi and Sohee Oh performed the statistical analysis. Ju Young Chang and Sue Shin analyzed data. Jeong Su Park and Sohee Oh contributed to the production and interpretation of the results. All authors drafted the article and revised it critically for important intellectual content, and approved the final article.

Conflicts of Interest: The authors declare no conflict of interest.

\section{References}

1. European Food Safety Authority; EFSA Panel on Contaminants in the Food Chain (Contam). Scientific opinion on lead in food. EFSA J. 2010, 8, 1570.

2. Joint FAO/WHO Expert Committee on Food Additives. Evaluation of Certain Food Additives and Contaminants; Sixty-First Report of the Joint FAO/WHO Expert Committee on Food Additives; WHO Technical Report Series, no. 922; WHO: Geneva, Switzerland, 2004.

3. Agency for Toxic Substances and Disease Registry. Toxicological Profile for Arsenic; Agency for Toxic Substances and Disease Registry, U.S. Department of Health and Human Services: Atlanta, GA, USA, 2007.

4. Agency for Toxic Substances and Disease Registry. Toxicological Profile for Cadmium; Agency for Toxic Substances and Disease Registry, U.S. Department of Health and Human Services: Atlanta, GA, USA, 2012. 
5. Gardner, R.M.; Kippler, M.; Tofail, F.; Bottai, M.; Hamadani, J.; Grander, M.; Nermell, B.; Palm, B.; Rasmussen, K.M.; Vahter, M. Environmental exposure to metals and children's growth to age 5 years: A prospective cohort study. Am. J. Epidemiol. 2013, 177, 1356-1367. [CrossRef] [PubMed]

6. Schoeters, G.; Den Hond, E.; Zuurbier, M.; Naginiene, R.; van den Hazel, P.; Stilianakis, N.; Ronchetti, R.; Koppe, J.G. Cadmium and children: Exposure and health effects. Acta Paediatr. Suppl. 2006, 95, 50-54. [CrossRef] [PubMed]

7. Akagi, H.; Grandjean, P.; Takizawa, Y.; Weihe, P. Methylmercury dose estimation from umbilical cord concentrations in patients with minamata disease. Environ. Res. 1998, 77, 98-103. [CrossRef] [PubMed]

8. Kaji, M.; Nishi, Y. Lead and growth. Clin. Pediatr. Endocrinol. 2006, 15, 123-128. [CrossRef] [PubMed]

9. Gilbert-Diamond, D.; Emond, J.A.; Baker, E.R.; Korrick, S.A.; Karagas, M.R. Relation between in utero arsenic exposure and birth outcomes in a cohort of mothers and their newborns from New Hampshire. Environ. Health Perspect. 2016, 124, 1299-1307. [CrossRef] [PubMed]

10. Lin, C.M.; Doyle, P.; Wang, D.; Hwang, Y.H.; Chen, P.C. Does prenatal cadmium exposure affect fetal and child growth? Occup. Environ. Med. 2011, 68, 641-646. [CrossRef] [PubMed]

11. Karagas, M.R.; Choi, A.L.; Oken, E.; Horvat, M.; Schoeny, R.; Kamai, E.; Cowell, W.; Grandjean, P.; Korrick, S. Evidence on the human health effects of low-level methylmercury exposure. Environ. Health Perspect. 2012, 120, 799-806. [CrossRef] [PubMed]

12. Hong, Y.C.; Kulkarni, S.S.; Lim, Y.H.; Kim, E.; Ha, M.; Park, H.; Kim, Y.; Kim, B.N.; Chang, N.; Oh, S.Y.; et al. Postnatal growth following prenatal lead exposure and calcium intake. Pediatrics 2014, 134, 1151-1159. [CrossRef] [PubMed]

13. Yang, H.; Huo, X.; Yekeen, T.A.; Zheng, Q.; Zheng, M.; Xu, X. Effects of lead and cadmium exposure from electronic waste on child physical growth. Environ. Sci. Pollut. Res. Int. 2013, 20, 4441-4447. [CrossRef] [PubMed]

14. Min, K.B.; Min, J.Y.; Cho, S.I.; Kim, R.; Kim, H.; Paek, D. Relationship between low blood lead levels and growth in children of white-collar civil servants in Korea. Int. J. Hyg. Environ. Health 2008, 211, 82-87. [CrossRef] [PubMed]

15. Centers for Disease Control and Prevention (CDC). CDC's Healthy Homes and Lead Poisoning Prevention Program. Available online: https://www.cdc.gov/nceh/lead/data/definitions.htm (accessed on 27 January 2017).

16. Schell, L.M.; Denham, M.; Stark, A.D.; Parsons, P.J.; Schulte, E.E. Growth of infants' length, weight, head and arm circumferences in relation to low levels of blood lead measured serially. Am. J. Hum. Biol. 2009, 21, 180-187. [CrossRef] [PubMed]

17. Patriarca, M.; Menditto, A.; Rossi, B.; Lyon, T.D.B.; Fell, G.S. Environmental exposure to metals of newborns, infants and young children. Microchem. J. 2000, 67, 351-361. [CrossRef]

18. Claus Henn, B.; Ettinger, A.S.; Hopkins, M.R.; Jim, R.; Amarasiriwardena, C.; Christiani, D.C.; Coull, B.A.; Bellinger, D.C.; Wright, R.O. Prenatal arsenic exposure and birth outcomes among a population residing near a mining-related superfund site. Environ. Health Perspect. 2016, 124, 1308-1315. [PubMed]

19. Kim, B.M.; Lee, B.E.; Hong, Y.C.; Park, H.; Ha, M.; Kim, Y.J.; Kim, Y.; Chang, N.; Kim, B.N.; Oh, S.Y.; et al. Mercury levels in maternal and cord blood and attained weight through the 24 months of life. Sci. Total Environ. 2011, 410-411, 26-33. [CrossRef] [PubMed]

20. Tian, L.L.; Zhao, Y.C.; Wang, X.C.; Gu, J.L.; Sun, Z.J.; Zhang, Y.L.; Wang, J.X. Effects of gestational cadmium exposure on pregnancy outcome and development in the offspring at age 4.5 years. Biol. Trace Elem. Res. 2009, 132, 51-59. [CrossRef] [PubMed]

21. Rollin, H.B.; Channa, K.; Olutola, B.G.; Odland, J.O. Evaluation of in utero exposure to arsenic in South Africa. Sci. Total Environ. 2017, 575, 338-346. [CrossRef] [PubMed]

22. Delvaux, I.; Van Cauwenberghe, J.; Den Hond, E.; Schoeters, G.; Govarts, E.; Nelen, V.; Baeyens, W.; Van Larebeke, N.; Sioen, I. Prenatal exposure to environmental contaminants and body composition at age 7-9 years. Environ. Res. 2014, 132, 24-32. [CrossRef] [PubMed]

23. Jedrychowski, W.A.; Perera, F.P.; Majewska, R.; Mrozek-Budzyn, D.; Mroz, E.; Roen, E.L.; Sowa, A.; Jacek, R. Depressed height gain of children associated with intrauterine exposure to polycyclic aromatic hydrocarbons (PAH) and heavy metals: The cohort prospective study. Environ. Res. 2015, 136, 141-147. [CrossRef] [PubMed] 
24. Dhooge, W.; Den Hond, E.; Koppen, G.; Bruckers, L.; Nelen, V.; Van De Mieroop, E.; Bilau, M.; Croes, K.; Baeyens, W.; Schoeters, G.; et al. Internal exposure to pollutants and body size in flemish adolescents and adults: Associations and dose-response relationships. Environ. Int. 2010, 36, 330-337. [CrossRef] [PubMed]

25. Chang, J.Y.; Park, J.S.; Shin, S.; Yang, H.R.; Moon, J.S.; Ko, J.S. Mercury exposure in healthy Korean weaning-age infants: Association with growth, feeding and fish intake. Int. J. Environ. Res. Public Health 2015, 12, 14669-14689. [CrossRef] [PubMed]

26. Zhai, Q.; Narbad, A.; Chen, W. Dietary strategies for the treatment of cadmium and lead toxicity. Nutrients 2015, 7, 552-571. [CrossRef] [PubMed]

27. Krebs, N.F. Food based complementary feeding strategies for breastfed infants: What's the evidence that it matters? Nutr. Today 2014, 49, 271-277. [CrossRef] [PubMed]

28. Lee, H.-S.; Cho, Y.-H.; Park, S.-O.; Kye, S.-H.; Kim, B.-H.; Hahm, T.-S.; Kim, M.; Ok Lee, J.; Kim, C.-I. Dietary exposure of the Korean population to arsenic, cadmium, lead and mercury. J. Food Compos. Anal. 2006, 19, S31-S37. [CrossRef]

29. Rebelo, F.M.; Caldas, E.D. Arsenic, lead, mercury and cadmium: Toxicity, levels in breast milk and the risks for breastfed infants. Environ. Res. 2016, 151, 671-688. [CrossRef] [PubMed]

30. Dorea, J.G.; Donangelo, C.M. Early (in uterus and infant) exposure to mercury and lead. Clin. Nutr. 2006, 25, 369-376. [CrossRef] [PubMed]

31. De Castro, C.S.; Arruda, A.F.; Da Cunha, L.R.; SouzaDe, J.R.; Braga, J.W.; Dorea, J.G. Toxic metals (Pb and $\mathrm{Cd}$ ) and their respective antagonists ( $\mathrm{Ca}$ and $\mathrm{Zn}$ ) in infant formulas and milk marketed in Brasilia, Brazil. Int. J. Environ. Res. Public Health 2010, 7, 4062-4077. [CrossRef] [PubMed]

32. Williams, P.N.; Villada, A.; Deacon, C.; Raab, A.; Figuerola, J.; Green, A.J.; Feldmann, J.; Meharg, A.A. Greatly enhanced arsenic shoot assimilation in rice leads to elevated grain levels compared to wheat and barley. Environ. Sci. Technol. 2007, 41, 6854-6859. [CrossRef] [PubMed]

33. Kim, J.Y.; Kim, W.I.; Kunhikrishnan, A.; Kang, D.W.; Kim, D.H.; Lee, Y.J.; Kim, Y.J.; Kim, C.T. Determination of arsenic species in rice grains using HPLC-ICP-MS. Food Sci. Biotechnol. 2013, 22, 1509-1513. [CrossRef]

34. Chou, W.C.; Chen, J.W.; Liao, C.M. Contribution of inorganic arsenic sources to population exposure risk on a regional scale. Environ. Sci. Pollut. Res. Int. 2016, 23, 14173-14182. [CrossRef] [PubMed]

35. Bae, M.; Watanabe, C.; Inaoka, T.; Sekiyama, M.; Sudo, N.; Bokul, M.H.; Ohtsuka, R. Arsenic in cooked rice in Bangladesh. Lancet 2002, 360, 1839-1840. [CrossRef]

36. Cleland, B.; Tsuchiya, A.; Kalman, D.A.; Dills, R.; Burbacher, T.M.; White, J.W.; Faustman, E.M.; Marien, K. Arsenic exposure within the Korean community (United States) based on dietary behavior and arsenic levels in hair, urine, air, and water. Environ. Health Perspect. 2009, 117, 632-638. [CrossRef] [PubMed]

37. Bae, H.S.; Kang, I.G.; Lee, S.G.; Eom, S.Y.; Kim, Y.D.; Oh, S.Y.; Kwon, H.J.; Park, K.S.; Kim, H.; Choi, B.S.; et al. Arsenic exposure and seafood intake in Korean adults. Hum. Exp. Toxicol. 2016. [CrossRef] [PubMed]

38. Kim, D.W.; Woo, H.D.; Joo, J.; Park, K.S.; Oh, S.Y.; Kwon, H.J.; Park, J.D.; Hong, Y.S.; Sohn, S.J.; Yoon, H.J.; et al. Estimated long-term dietary exposure to lead, cadmium, and mercury in young Korean children. Eur. J. Clin. Nutr. 2014, 68, 1322-1326. [CrossRef] [PubMed]

39. Park, C.; Hwang, M.; Kim, H.; Ryu, S.; Lee, K.; Choi, K.; Paek, D. Early snapshot on exposure to environmental chemicals among Korean adults-results of the first Korean national environmental health survey (2009-2011). Int. J. Hyg. Environ. Health 2016, 219, 398-404. [CrossRef] [PubMed]

40. Park, J.S.; Chang, J.Y.; Hong, J.; Ko, J.S.; Seo, J.K.; Shin, S.; Lee, E.H. Nutritional zinc status in weaning infants: Association with iron deficiency, age, and growth profile. Biol. Trace Elem. Res. 2012, 150, 91-102. [CrossRef] [PubMed]

41. Borgna-Pignatti, C.; Marsella, M. Iron deficiency in infancy and childhood. Pediatr. Ann. 2008, 37, 329-337. [PubMed]

42. Lozoff, B.; Beard, J.; Connor, J.; Barbara, F.; Georgieff, M.; Schallert, T. Long-lasting neural and behavioral effects of iron deficiency in infancy. Nutr. Rev. 2006, 64, S34-S43. [CrossRef] [PubMed]

43. Sreedharan, R.; Mehta, D.I. Gastrointestinal tract. Pediatrics 2004, 113, 1044-1050. [PubMed]

44. World Health Organization. Anthro Software (Version 3.2.2, January 2011). Available online: http://www. who.int/childgrowth/software/en (accessed on 1 April 2017).

45. Centers for Disease Control and Prevention. Blood mercury levels in young children and childbearing-aged women-United States, 1999-2002. MMWR Morb. Mortal Wkly. Rep. 2004, 53, 1018-1020. 
46. Norma, B.L.; Richard, S. Iron-deficiency anemia. In Nelson Textbook of Pediatrics, 19th ed.; Kliegman, R.M., Stanton, B.F., St. Geme, J.W., Schor, N.F., Behrman, R.E., Eds.; Elsevier: Philadelphia, PA, USA, 2011; p. 1655.

47. Ha, M.; Kwon, H.J.; Leem, J.H.; Kim, H.C.; Lee, K.J.; Park, I.; Lim, Y.W.; Lee, J.H.; Kim, Y.; Seo, J.H.; et al. Korean environmental health survey in children and adolescents (KOREHS-C): Survey design and pilot study results on selected exposure biomarkers. Int. J. Hyg. Environ Health 2014, 217, 260-270. [CrossRef] [PubMed]

48. Kim, Y.M.; Chung, J.Y.; An, H.S.; Park, S.Y.; Kim, B.G.; Bae, J.W.; Han, M.; Cho, Y.J.; Hong, Y.S. Biomonitoring of lead, cadmium, total mercury, and methylmercury levels in maternal blood and in umbilical cord blood at birth in South Korea. Int. J. Environ. Res. Public Health 2015, 12, 13482-13493. [CrossRef] [PubMed]

49. Schulz, C.; Angerer, J.; Ewers, U.; Heudorf, U.; Wilhelm, M. Revised and new reference values for environmental pollutants in urine or blood of children in Germany derived from the German environmental survey on children 2003-2006 (GerES IV). Int. J. Hyg. Environ. Health 2009, 212, 637-647. [CrossRef] [PubMed]

50. Lindberg, A.L.; Kumar, R.; Goessler, W.; Thirumaran, R.; Gurzau, E.; Koppova, K.; Rudnai, P.; Leonardi, G.; Fletcher, T.; Vahter, M. Metabolism of low-dose inorganic arsenic in a central European population: Influence of sex and genetic polymorphisms. Environ. Health Perspect. 2007, 115, 1081-1086. [CrossRef] [PubMed]

51. Mayo Foundation for Medical Education and Research. Arsenic, Blood; 2013. Available online: http:/ /www. mayomedicallaboratories.com/test-catalog/clinical+and+interpretive/8645 (accessed on 11 February 2017).

52. Concha, G.; Nermell, B.; Vahter, M.V. Metabolism of inorganic arsenic in children with chronic high arsenic exposure in northern Argentina. Environ. Health Perspect. 1998, 106, 355-359. [CrossRef] [PubMed]

53. Schulz, C.; Conrad, A.; Becker, K.; Kolossa-Gehring, M.; Seiwert, M.; Seifert, B. Twenty years of the German environmental survey (GerES): Human biomonitoring-Temporal and spatial (west Germany/east Germany) differences in population exposure. Int. J. Hyg. Environ. Health 2007, 210, 271-297. [CrossRef] [PubMed]

54. Parajuli, R.P.; Umezaki, M.; Fujiwara, T.; Watanabe, C. Association of cord blood levels of lead, arsenic, and zinc and home environment with children neurodevelopment at 36 months living in Chitwan valley, Nepal. PLoS ONE 2015, 10, e0120992. [CrossRef] [PubMed]

55. Hall, M.; Chen, Y.; Ahsan, H.; Slavkovich, V.; van Geen, A.; Parvez, F.; Graziano, J. Blood arsenic as a biomarker of arsenic exposure: Results from a prospective study. Toxicology 2006, 225, 225-233. [CrossRef] [PubMed]

56. Lee, J.W.; Lee, C.K.; Moon, C.S.; Choi, I.J.; Lee, K.J.; Yi, S.M.; Jang, B.K.; Yoon, B.J.; Kim, D.S.; Peak, D.; et al. Korea national survey for environmental pollutants in the human body 2008: Heavy metals in the blood or urine of the Korean population. Int. J. Hyg. Environ. Health 2012, 215, 449-457. [CrossRef] [PubMed]

57. Hata, A.; Endo, Y.; Nakajima, Y.; Ikebe, M.; Ogawa, M.; Fujitani, N.; Endo, G. HPLC-ICP-MS speciation analysis of arsenic in urine of Japanese subjects without occupational exposure. J. Occup. Health 2007, 49, 217-223. [CrossRef] [PubMed]

58. World Health Organization. Guidlines for Driniking-Water Quality, 3rd ed.; Recommendations Volume 1; World Health Organization: Geneva, Switzerland, 2004.

59. Ahmed, S.; Rekha, R.S.; Ahsan, K.B.; Doi, M.; Grander, M.; Roy, A.K.; Ekstrom, E.C.; Wagatsuma, Y.; Vahter, M.; Raqib, R. Arsenic exposure affects plasma insulin-like growth factor 1 (IGF-1) in children in rural Bangladesh. PLoS ONE 2013, 8, e81530. [CrossRef] [PubMed]

60. Grandjean, P.; Landrigan, P.J. Developmental neurotoxicity of industrial chemicals. Lancet 2006, 368, 2167-2178. [CrossRef]

61. Marchiset-Ferlay, N.; Savanovitch, C.; Sauvant-Rochat, M.P. What is the best biomarker to assess arsenic exposure via drinking water? Environ. Int. 2012, 39, 150-171. [CrossRef] [PubMed]

62. Haschke, F.; van't Hof, M.A.; Euro-Growth Study Group. Euro-growth references for breast-fed boys and girls: Influence of breast-feeding and solids on growth until 36 months of age. J. Pediatr. Gastroenterol. Nutr. 2000, 31 (Suppl. 1), S60-S71. [CrossRef] [PubMed]

63. Fangstrom, B.; Moore, S.; Nermell, B.; Kuenstl, L.; Goessler, W.; Grander, M.; Kabir, I.; Palm, B.; Arifeen, S.E.; Vahter, M. Breast-feeding protects against arsenic exposure in Bangladeshi infants. Environ. Health Perspect. 2008, 116, 963-969. [CrossRef] [PubMed]

64. Maguire, J.L.; Salehi, L.; Birken, C.S.; Carsley, S.; Mamdani, M.; Thorpe, K.E.; Lebovic, G.; Khovratovich, M.; Parkin, P.C. Association between total duration of breastfeeding and iron deficiency. Pediatrics 2013, 131, e1530-e1537. [CrossRef] [PubMed] 
65. Hong, J.; Chang, J.Y.; Shin, S.; Oh, S. Breastfeeding and red meat intake are associated with iron status in healthy Korean weaning-age infants. J. Korean Med. Sci. 2017, in press.

66. Kim, Y.; Park, S. Iron deficiency increases blood concentrations of neurotoxic metals in children. Korean J. Pediatr. 2014, 57, 345-350. [CrossRef] [PubMed]

67. Lynch, H.N.; Greenberg, G.I.; Pollock, M.C.; Lewis, A.S. A comprehensive evaluation of inorganic arsenic in food and considerations for dietary intake analyses. Sci. Total Environ. 2014, 496, 299-313. [CrossRef] [PubMed]

(C) 2017 by the authors. Licensee MDPI, Basel, Switzerland. This article is an open access article distributed under the terms and conditions of the Creative Commons Attribution (CC BY) license (http://creativecommons.org/licenses/by/4.0/). 